\title{
Resensie-artikel
}

\section{Die deurlopende koord}

\author{
Heilna du Plooy \\ Skool vir Tale en Kunste (Afrikaans en Nederlands) \\ Potchefstroomse Universiteit vir $\mathrm{CHO}$ \\ POTCHEFSTROOM \\ E-pos: afnhigdp@puknet.puk.ac.za
}

\author{
Abstract \\ The endless thread
}

This article discusses the volume of short stories, Boereoorlogstories, which was compiled and edited by Jeanette Ferreira. The stories are all about the Anglo-Boer War (1899-1902) and though some of the stories simply retell history from the point of view of specific individuals, some of the stories are indeed fine examples of postmodernist fiction. In the best stories in the volume the narrators engage with history in a number of ways: by indicating the fallacies of historiography, by contrasting little narratives with the master narrative of official historical documents, by emphasizing the textuality of history and the necessity of retelling the past. Personalized history and personalized interpretations of historical facts and historical documents are used in attempting to find or create new identities. The use of historiographical metafiction enables these narrators to interact with a present which is so complex and still so near that it can only be approached indirectly through stories

Ferreira, Jeanette (samest. \& red.) 1998. Boereoorlogstories.

Pretoria : Van Schaik 325 p. Prys: R89,95. ISBN 0627024025.

\section{Inleiding}

In die bundel Boereoorlogstories het Jeanette Ferreira as samesteller en redakteur "34 verhale oor die oorlog van 1899-1902" bymekaargebring. Die 
verhale is spesifiek vir die bundel geskryf en is dus "nuwe" verhale oor 'n "ou" onderwerp, sommige deur ervare en bekende skrywers in Afrikaans en ander deur jonger en nuwe skrywers. 'n Mens sou kon vra of hierdie bundel maar net nog een van die publikasies is wat na aanleiding van die herdenking van die Anglo-Boereoorlog geskryf is, maar wat gou daarna vergeet sal word en op rakke stof sal vergader tot met 'n volgende herdenking van die oorlog? Herdenkingsliteratuur, hetsy van historiese, politieke, staatkundige, oorlogskundige, ideologiese of literêre aard verskyn tans in oorvloed en daar word soveel konferensies en toere gereël dat die herdenking byna as 'n soort bedryf gesien kan word, met groot binnelandse en buitelandse belangstelling.

Hierdie verhalebundel is inderdaad meer as 'n geleentheidspublikasie aangesien 'n verskeidenheid uiters boeiende aspekte in die verhale na vore kom. Vanselfsprekend is al die verhale nie ewe "goed" nie, nie ewe oorspronklik of tot dieselfde mate in staat om die waterare diep onder die oppervlak oop te boor nie. Daar is ' $n$ hele aantal van die verhale wat gewoonweg handel oor treffende insidente uit die periode van die oorlog, insidente wat nie noodwendig dokumentêr "waar" is nie, maar wat tog as waar oorgelewer is of wat in lyn lê met dit wat waar sou kon wees. Hierdie verhale en vertellings is oortuigend en leesbaar genoeg en hoewel hulle in die meeste gevalle daarin slaag om iets van die atmosfeer en die omstandighede van die oorlog te representeer, is hulle nie veel meer as realistiese, populêr-historiese verhale nie.

Veel interessanter is die verhale wat op 'n meer komplekse wyse met die geskiedenis in wisselwerking tree. In hierdie uitgebreide resensie wil ek spesifiek aandag gee aan ' $n$ tipering van daardie verhale wat in denke en tegniek dieselfde eienskappe en tendense van die kontemporêre ernstiger prosa vertoon al word hulle hier in populêre geselskap aangebied en al is hulle steeds toeganklike leesstof. Dit gaan dus nie primêr om 'n evaluerende resensie nie, ook nie om uitgebreide analises van spesifieke verhale nie - hoewel enkele verhale wel 'n indringende analise regverdig - maar hoofsaaklik om 'n beskrywing en bespreking van tematiese en tekstuele aspekte wat lesers op interessante aspekte van die tekste kan wys.

\section{Voorwoord en historiese agtergrond}

In die "Voorwoord en oorsig van die oorlog" gee die redakteur 'n bondige uiteensetting van die opset van die bundel en 'n paar tegniese sake. Daarna volg 'n kort oorsig van historiese gegewens wat belangrike inligting oor getalle en wapens insluit. Die basiese omstandighede van sowel die burgers as die Britte word kortliks uiteengesit en die onderlinge verhoudinge tussen byvoorbeeld die burgers, bittereinders, rebelle en verraaiers word verduidelik. Belangrike gebeurtenisse wat die verloop van die oorlog bepaal het, soos die suksesse en verliese aan albei kante, word gegee. Hierdie kontroleerbare en saaklike feite (wat dus werklik as "feite" beskou kan word) sluit inligting in wat miskien al 
vergeet is, nooit presies en duidelik bekend was nie of deur oorleweringe wollerig en vaag en onnoukeurig geword het. Dit is egter veral belangrik vir 'n jonger generasie lesers (en vir toekomstige lesers) wat nie meer oor eerste- of tweedehandse kennis van die meer subtiele fasette van die oorlog beskik nie.

Daar word tans algemeen aanvaar dat geskiedenis tot 'n groot mate (selfs miskien geheel en al) 'n rekonstruksie is van gebeure, meestal met die oog op 'n nuwe doelstelling soos die ontwikkeling of bevordering van ideologiese oogmerke. Tog is daardie feite wat kontroleerbaar is altyd verhelderend, omdat dit 'n raamwerk verskaf waarteen die menslike belewenis geplaas en verstaan kan word.

Die basiese gegewens oor die oorlog, wie daar was, hoeveel mense en hoeveel wapens, die kleiner onderlinge skeidinge en verdelings, moet bekend wees om byvoorbeeld die balans in mag tussen die deelnemende partye te illustreer. Brittanje was op die hoogtepunt van sy imperiale mag (wat grootliks ekonomies georiënteer was) (Wallbank et al., 1981:261) en 'n aktiewe speler in 'n wêreld wat gekenmerk is deur 'n disekwilibrium in mag tussen kulture en lande. Teenoor die wêreldmag word die Boererepublieke deur historici getipeer as 'n konserwatiewe gemeenskap met 'n lokale ekonomie, wat dus nie eers werklik nasionaal gefunksioneer het nie, wat nog te sê internasionaal (Findley \& Rothney, 1990:12-15). Weliswaar is hierdie "lokale ekonomie" deur die ontdekking van goud en diamante in die hoofstroom van die internasionale kapitalisme ingesuig, maar die daaglikse bestaan, die lewenstyl en denkwyse van die boeregemeenskap is slegs indirek hierdeur geraak en nie ingrypend verander of verruim nie.

Hierdie "klein" oorlog (klein in vergelyking met oorloë wat later in die twintigste eeu sou plaasvind) was op 'n manier tiperend van ontwikkelinge wat die eerste gedeelte van die twintigste eeu sou oorheers, juis met betrekking tot die ongelykhede in mag en die manier waarop dit gesien is deur die Europese moondhede. Dit was vanuit Europese en Britse perspektief aanvaarbaar dat swakker nasies en ekonomieë deur die sterkeres oorgeneem sou word en dat hierdie sterk lande hulself nog sterker kon maak deur die ekonomiese bronne van verowerde lande vir eie gewin te ontgin. Hiermee saam was daar die aanvaarding van kulturele en morele superioriteit. Die opvattings wat in die tyd van die oorlog as waar en geldig beskou is, word egter tans deur kontemporêre historici bevraagteken en ondermyn: "The differences considered here do not express dominance and inferiority in any terms other than the power-related ones that have created such sharp divisions in the modern world" (Findley \& Rothney, 1990:13).

Historiese gegewens en sienings is dus uiters broos en selfs op amptelike vlak word daar tans aanvaar dat dit blootgestel is aan voortdurende herinterpretasie. Hoeveel te meer onstabiel en vlugtig word die geskiedenis as enkelinge en selfs 
onbelangrike individue vanuit eie (dikwels eensydige) ervaring daarna kyk of op grond van flardes oorlewering daaroor kommentaar lewer. En tog is persoonlike weergawes van die geskiedenis, ongeag die dokumentêre korrektheid daarvan, belangrik en is die vertel daarvan waardevol.

\section{Die verlede in verhale herskep}

Wat van die bundel Boereoorlogstories as geheel gesê moet word, is dat daar uiteindelik ' $n$ veelfasettige en geskakeerde beeld van die oorlog uit die verhale na vore kom. Daar is verhale oor die lyding en swaarkry van vrouens, op plase, op trek en in die kampe, daar is verhale oor bittereinders en "joiners", oor onversetlikheid en beginselvastheid, maar ook oor diegene wat onder druk en vrees meegegee het ("Bertie kom verby" van Eleanor Baker, "Die soettandoorlog" van Pirow Bekker, "Jy sê teken, Botman" van Henriette Grové). Daar is verhale wat die edel aspekte van mense belig, maar ook dié wat toon hoe mense in oorlogstyd - net soos in vredestyd - swak en sleg kan wees (" De Emigratie', 30 Mei 1901" van Biebie de Villiers, "Jy sal jou gat sien" van Hans du Plessis). Die verhale oor individue wat buite die groot kategorieë van Boer en Brit val, verhale oor onder meer swart mense, bruin mense, Jode en Russe, werk daartoe mee dat die bundel allermins 'n eensydige of geromantiseerde beeld van die oorlog gee (vgl. "A native named Dolley" van Konstant van Huyssteen, "Die Poolse Jood en die perdedief" van Marlene van Niekerk, "Anna Pavlova Zvereva (1881-1952)" van Melanie Grobler).

Dit gaan hier baie duidelik oor die skryf van kleingeskiedenisse, individuele geskiedenisse wat staan teenoor die amptelike geskiedenis wat as meesterverhaal opgeteken en geyk is (vgl. Van Heerden, 1997:44-45). Die verhale gee 'n beeld van die oorlog wat deels met die geykte versie ooreenstem, maar wat belangrike aanpassings en toevoegings maak. Die groot en deurlopende lyne word as't ware ingevul en aangevul deur persoonlike detail. Juis in die toevoegings en aanpassings lê die interessantste inligting opgesluit, kom smart en lag, waardigheid en verlies saam tot bestaan. Dit is in besonder waar van "Kos" van Gretel Wijbenga, waarin vertel word hoe vroue die hensopper wat hulle geld skuld, afrem deur net elke dag voor sy tent te gaan sit en wag. Aan die hand van die "nietige" insident (wat nogtans vertel van moed en humorsin en 'n aanvoeling vir ironie by die karakters) word dan ten slotte geillustreer hoe dit wat vir mense aan die een kant van 'n oorlog oorlewing is, vir die ander kant stof vir ligte vermaaklike vertellings is.

Sulke verhale kan gesien word as elegieẽ waarin "(l)oss, suffering and shame are revisited" en die vertelhandeling as sodanig is waardevol omdat "the ability of artistic transactions to perform an elegiac function" nie onderskat moet word nie (De Kok, 1998:61). Net soos wat daar in die onlangse verlede by die Waarheids- en Versoeningskommissie verhale vertel is en die vertelling op sigself 'n helende funksie kon hê, is daar direk na die Anglo-Boereoorlog ook 
vertel, oor en oor vertel, ter wille van heling, ter wille van die opbou van 'n nuwe sekuriteit, ter wille van die bevestiging van die waardestelsels van die mense.

Die generasies van vier of vyf dekades later het moeg geword vir die oorlogstories. Met verloop van tyd het dit ook duidelik geword dat dié verhale van smart en lyding gebruik is in die monstering van 'n ideologiese krag wat moes beding vir mag in die hede en die toekoms. Die gebruik en misbruik van verhale oor lyding is 'n bekende verskynsel in verskillende kulture, veral waar die verhale deur amptelike instansies toegeèien word.

Die kleingeskiedenis, die persoonlike belewenis, hetsy self vertel of in herinnering gebring, vertoon egter ook ander eienskappe. Omdat dit nie in die eerste plek in die magspel saamspeel nie, word oorvertellings op persoonlike vlak dikwels gebruik om ervaring te verwerk en daarvan sin te maak, maar ook om te bewaar of gebroke dinge te probeer herstel. Weemoed om lyding en die behoefte om dit wat vir altyd verbygegaan het, in die geheue te koester, kom dikwels en in alle literature en kulture in verhale voor. Derek Walcott het die effek van die versplintering van die Antilliaanse gemeenskap deur die kolonialisme op besonder poëtiese wyse beskryf in sy Nobelprystoespraak:

Break a vase, and the love that reassembles the fragments is stronger than that love which took its symmetry for granted when it was whole. The glue that fits the pieces is the sealing of the original shape. It is such a love that reassembles our African and Asiatic fragments, the cracked heirlooms whose restoration shows its white scars. (Aangehaal deur De Kok, 1998:62).

Daar het in die afgelope dekades 'n volgende groot politieke golf oor die mense van Suid-Afrika gespoel, en nuwe verhale van nuwe onlangser lyding word vertel. Op 'n bepaalde manier het die resente geskiedenis die Boereoorlogvertellinge in 'n groot mate ontdaan van die ideologiese funksie en nut wat hulle in die eerste helfte van die eeu gehad het, en dit kan as 'n soort bevryding gesien word. Hierdie stories hoef nie meer die inisiële heling te bewerkstellig nie en kan ook nie meer gebruik word in die meesterdiskoers van die hede nie. Tog speel hulle steeds ' $n$ belangrike rol in die bewaring en die voortdurende rekonstruksie van die verlede deur die elegiese in-herinnering-roep van dit wat verbygegaan het in die verlede van ' $n$ bepaalde groep van die Suid-Afrikaanse bevolking

Die problematiek wat in die verhale aan die orde kom, het 'n bepalende rol gespeel in die ontwikkeling van die kulturele mentaliteit en identiteit van Afrikaners, meer so as in die geval van ander bevolkingsgroepe wat ook aan die oorlog deel gehad het en daaronder gely het, waarskynlik omdat die nederlaag in die eerste plek as 'n nederlaag vir die Afrikaners van die twee noordelike 
republieke gesien is. Nou word verhale na 'n honderd jaar vertel, om te onthou maar ook om deur die herinnering in 'n spieël te kyk waarin die bestanddele en die sleutels van die kontemporêre psige weerkaats staan en ondersoek kan word.

\section{Die kontekste van die bundel}

Die verhale in hierdie bundel wat vir my die boeiendste was, was dié wat handel oor familiegeskiedenisse, dié wat openlik gekoppel word aan mense wat werklik geleef het en wat boonop vertel word deur die nasate self. Dit is opvallend in hoeveel verhale daar ' $n$ implisiete of eksplisiete outobiografiese verbintenis of verband aanwesig is. Dit is hierdie verhale wat 'n mens daarvan bewus maak hoe belangrik die invalshoek en die historiese moment van skryf is en ook hoe belangrik die moment van resepsie van 'n teks is.

Die bundel Boereoorlogstories verskyn laat in 1998 en daar kan onder meer twee stelle faktore beskryf word, wat die periode van skryf en van resepsie van die verhale bepalend beïnvloed.

Daar is in die eerste instansie die historiese faktore, die gebeure en omstandighede in die werklikheid, die totale konteks of liewer die kontemporêre interteks.

Die honderdjarige herdenking van die oorlog is voor hande en daar is tans hernude belangstelling in die gegewens wat al ietwat vervaag het vanweë die verloop van tyd en vanweë groter en dringender probleme in Suid-Afrika. Die ingrypende politieke veranderinge in Suid-Afrika is nog besig om beslag te kry in die praktyk en die proses van die afwenteling van die erfenis van apartheid kan gesien word as die finale fase van dekolonialisering. Daar heers tans in Suid-Afrika 'n klimaat van onthulling (versinnebeeld deur die Waarheids- en Versoeningskommissie), waarin die opneem van skuld en vergiffenis prominent is, maar hierdie ingesteldheid strek wyer. Veral die Westerse wêreld is besig met ingrypende selfondersoek oor die koloniale (imperialistiese en kapitalistiese) verlede. Die Anglo-Boereoorlog staan midde-in die koloniale en postkoloniale debat, aangesien dit ' $n$ inherent koloniale (kolonialiserende) oorlog was. Daarby kom dat die bevryding van die Britse koloniale bande in die loop van die eerste helfte van die eeu gevolg is deur 'n wit nasionalistiese regering, wat die swart bevolking van Suid-Afrika net as 'n volgende koloniale fase beskou het. Die afloop van hierdie geskiedenis het daartoe gelei dat Afrikaners tans 'n identiteitskrisis beleef, wat deels uit eie omstandighede groei, maar ook aansluit by die meer algemene identiteitsproblematiek en 'n bewustheid van kulturele identiteit in die Westerse lande.

Verder val hierdie spesifieke fokus op die verlede saam met die eeuwisseling en ook die millenniumwisseling, 'n periode wat mense in elk geval bring tot bestekopname en selfondersoek. Die intellektuele klimaat waarin daar tans geleef word, is dié van die postmodernisme. Dit is die een stroming of tydsgees 
wat tot so 'n mate gepopulariseer is dat almal daarvan bewus is en dat dit deur mense op alle vlakke van die lewe ervaar word. Sake soos die problematisering van die geskiedenis, die bevraagtekening van feite wat vroeër aanvaar is, die relativering van die belang van sake en gebeure in die hede en die verlede, die skeptisisme oor die outentisiteit van gegewens en aanvaarding daarvan dat feit en fiksie moeilik onderskeibaar is, is nie tot studeerkamers en filosofiese gesprekke beperk nie, maar vorm deel van die normale manier waarop mense inderdaad die werklikheid belewe (Du Plooy, 1998:74-83).

Die tweede stel faktore wat saam met die historiese omstandighede die atmosfeer beinvloed waarin literatuur in die negentigerjare verskyn, is die literêre denke van die tyd.

Die hele sprektrum van postmodernistiese literêre strategieë, maar veral die postmodernistiese filosofiese onderbou wat die kontemporêre literatuur en die gesprekke oor die literatuur kenmerk, speel in die skryf en die resepsie van hierdie bundel 'n rol. Die lesers en die skrywers (waarvan sommige erkende en ervare skrywers is) kommunikeer immers via die verhale juis in terme van die kontemporêre literêre parameters. Dit gaan dus om 'n eksplisiete bewustheid van dinge soos die verbrokkeling van insig en kennis (inhoudelik, tematies en tegnies), die problematisering van die geskiedenis in historiografiese metafiksie, die vervaging van grense tussen feit en fiksie, die dekonstruksie van meesterverhale, die ontmaskering van die legendes van die verlede en selfs die demonisering van die amptelike en aanvaarde versies van die geskiedenis. Verder is die desentralisering van die subjek en die onvermoe om die self te ken, sy herkoms of sy toekoms te kan peil, tipiese postmodernistiese kwessies (Van Heerden, 1997:11-64).

\section{Geskiedenis, geheue en die subjek}

Dit is opvallend hoe die historiese en literêre kontekste (in der waarheid eerder intertekstuele netwerke of selfs labirinte) in die meer gekompliseerde verhale in die bundel Boereoorlogstories figureer. Die verhale kan nie gelees word net om die verlede op te roep nie, ook nie om of romantiserend of eensydig demoniserend na die verlede te kyk nie.

Dit is voor die hand liggend dat stories klein geskiedenisse vertel - en die meer gewone verhale doen dit inderdaad, maar ander verhale plaas die klein geskiedenis eksplisiet teenoor die meesterverhaal en toon so die onbetroubaarheid, die onnoukeurigheid, die arbitrêre aard van die meesterverhaal aan. In die verhaal van Johan en Elize Botha, "Op soek na die Slag van Rooipoeierspruit", word geskiedskrywing en oorlewering en die daadwerklike kontemporêre soek na oorblyfsels bymekaargebring. Die geskrewe geskiedenis word geplaas teenoor die funksie van die eie verhaal. Die verhaal gaan uiteindelik daaroor dat mense mekaar deur hulle stories leer ken en bly ken en hoe belangrik dit is dat 
hierdie stories vertel word. Die amptelike versie van die geskiedenis laat die menslikheid en warmte waarin mense kan lewe, verlore gaan en daarom moet mense self vertel en bly vertel. Meer nog, die aktıwiteit van die vertel van stories oor die verlede is belangriker as die dokumentêre bewysbaarheid van die feite en gegewens waaroor dit gaan.

Hierdie verhaal maak direk die stelling dat mense mekaar deur hulle stories ken. Die verhaal eindig met die woorde: "Ons begin weer die ou verhale vertel", maar dit kom nadat die hele verhaal daaraan gewy is om die ongrypbare en onnaspeurbare aard van die verlede te illustreer. Die stories wat mense vertel, gaan dus nie (net) oor die verlede nie, maar meer om die vasstelling van identiteit, die soeke na die self en die soeke na kennis van mekaar.

Hierdie verhaal, net soos baie ander, onder meer Kerneels Breytenbach se "Oorlog ter plaatse", Margaret Bakkes se "Oorlog is oorlog is oorlog", Gretel Wijbenga se "Kos", P.G. du Plessis se "Ons mond" en P.J. Haasbroek se "Oorlogverhaal", gaan oor oorleweringe binne 'n familie. Die eksplisiete aanduiding van die "waarheidselement" of die "outentisiteit" van die stories deur verwysings na familieverwantskap tussen verteller en karakters en die gebruik van herkenbare name word dadelik weer bevraagteken en gekompliseer op verskeie maniere. In sommige verhale word die oorgelewerde gegewens of herinnering met dokumente vergelyk of daaraan getoets en so word die potensiële onbetroubaarheid van die verskillende weergawes erken. Wat verder 'n soort integriteit aan die verhale gee, is die openlikheid waarmee die verlede aan die orde gestel word. Daar word nie weggeskram daarvan om te noem dat party voorsate aan die "verkeerde" kant was in die oorlog nie, ook nie dat sommige in die politieke ontwikkelinge na die oorlog aan 'n ander kant was as wat die verteller self sou wees nie (vgl. Breytenbach se "Oorlog ter plaatse" en Haasbroek se "Oorlogverhaal").

Maar die ontluistering van die verlede kry hier 'n bykomende dimensie. Honderd jaar is lank genoeg dat die vertellers hulle nie meer aangetas voel deur die dade van die voorgeslagte nie en daarom is dit nie nodig om te vervloek of te heilig of te verskoon nie. Dit is nou makliker (miskien nou eers moontlik) om met ' $n$ helder blik na die verlede te kyk en daarom kan daar beter stories daaroor geskryf word. Die verhalende gegewens kom staan voor die leser wat vanuit die hede self oordeel en beoordeel of veroordeel. Die oop en nugter blik vanuit die hede word myns insiens meer deur die hede bepaal as deur die verlede.

Die verlede, spesifiek die geskiedenis van die oorlog wat so 'n bepalende rol in die psige van die Afrikaners gespeel het, word hier 'n soort metafoor, 'n vehicle waarmee en waardeur die vertellers die hede beskou. Margaret Bakkes soek 'n verklaring vir 'n persoonlikheid in die invloed van gebeure tydens en na afloop van die oorlog op gesinsverhoudinge. Kerneels Breytenbach soek eksplisiet na 
selfdefinisie deur die verlede te verhaal en P.G. du Plessis skeer inderdaad sy oupa se mond saam met en in sy eie mond in die spieël oop.

Want die verlede, die hede en die toekoms is 'n aaneenlopende koord, soms in meer gekompliseerde patrone gevleg, soms in verskillende kleure, soms dunner en soms dikker, maar 'n koord waarvan minstens sommige drade en kleure deurloop sodat spesifieke aspekte altyd weer terugvindbaar is. Die soek na kennis van en begrip vir die drade van die verlede is belangrik of self essensieel vir die toekoms, hoe veranderlik en verraderlik hierdie drade ook al is. Die gedagte dat die verlede die toekoms bepaal via die hede is breed uitgewerk deur Heidegger (1949:328) en volgens hom behoort die bemoeienis met die verlede eerder ' $n$ gerigtheid op die toekoms te wees as 'n vashou aan die verlede. In hierdie spesifieke verhale lyk dit inderdaad of die familiegeskiedenis ter wille van die toekoms afgestof, herdink en weer verwoord word

Die verhale waarin hede en verlede gejukstaponeer word, kan beskou word as voorbeelde van historiografiese metafiksie, waarin verskeie postmodernistiese strategiee gebruik word en waarin die postmodernistiese bemoeienis met en komplisering van die verlede as teks weer tekstueel uitgewerk word (vgl. Brink, 1998:29-42, Van Heerden, 1998:21-34). Die verhale is dan ook gemoeid met dieselfde tematiek as verskeie ander resente boeke van Afrikaanse skrywers, onder meer Breyten Breytenbach se Dog Heart (1998), André P. Brink se Inteendeel (1993), Sandkastele (1995) en Duiwelskloof (1998) en Christoffel Coetzee se Op soek na generaal Mannetjies Mentz (1998).

Die huidige politieke omstandighede vта om nuwe definisies en oriêntasies, om nuwe selfbeskouinge, om die herontwerp van 'n selfbeeld uit die bestanddele van die verlede en van die hede. Daar is met ander woorde 'n behoefte aan 'n siening van identiteit, aan 'n identiteit self, waarmee die toekoms ingegaan kan word. Hierdie soeke na identiteit is onderliggend aan verhale soos dié van P.G. du Plessis en Kerneels Breytenbach. Die identeitsproblematiek sluit aan by verskeie ander kontemporêre Afrikaanse romans soos onder meer Die Olifantjagters (1997) van Piet van Rooyen en Annerkant die longdrop (1998) van Anoeshka von Meck.

In die postmoderne wêreld is dit egter ontsettend moeilik om 'n begrip van identiteit te hê of te vind en om te weet waarheen jy op pad is. Hierdie tema is prominent in die groot hoeveelheid outobiografiese literatuur wat tans verskyn (vgl. Musschoot, 1998). Die onsekerhede waarmee die mens van ons tyd gekonfronteer is, word deur die Nederlandse digter Robert Anker in 'n lang epiese gedig, "Goede manieren", uitgewerk: 
... wij zijn maar klein hier zonder matje, maar groter is de ruggegraat van eigen makelij, de ratio die ons behoed maar wat ons samenhield gebroken heeft, elke deur geopend heeft en staan we rillend op de tocht, gezond en goed gekleed, bevrijd tot op het bot, niet bang meer maar nerveus: te kiezen wie je bent, te denken wat je kan.

(Fokkema, 1997)

Dit lyk dus of hierdie Boereoorlogstories op 'n verskeidenheid maniere aansluit by tendense wat tans die verhaalkuns oorheers. Wat egter tog in die meeste van die Boereoorlogstories opval, is die energie en spontaneiteit waarmee geskryf en vertel word. 'n Mens sou oor redes daarvoor kon bespiegel, byvoorbeeld dat so 'n bundel geen literêre reputasie kan maak of breek nie en dat die skrywers dus vryer en meer onbevange kon skryf of dat die verhale uitgesoek is met 'n bepaalde aanvoeling. Ek glo egter dat die Anglo-Boereoorlog so in die grein van Afrikaanse mense ingegroei is dat dit ' $n$ inherente onderdeel van hulle samestelling en verwysingsraamwerk is, natuurlik en ten volle geïnternaliseerd. Watter mening die skrywers ook al daaroor huldig, hulle ken die feite en die verdigsels oor die oorlog, hulle ken die mense waaroor dit gaan, hulle ken die landskap waarin dit gebeur het, hulle ken die omstandighede en gesindhede van die mense in, voor en na die oorlog. Die skrywers weet ook dat hulle lesers (minstens vir die huidige periode) oor dieselfde verwysingsraamwerk beskik. Die navorsing en kontekstuele insig in die meeste verhale deurstaan die toets van die vanselfsprekende kennis en fyn aanvoeling vir die dinge onder die oppervlak. En so skryf die skrywers met selfvertroue uit hulle bloed en murg uit.

Deur honderd jaar later oor 'n saak te skryf het die voordeel dat die afstand perspektief gee terwyl warmte en menslikheid behou kan word. Die beskouinge van die verlede in die beste verhale in hierdie bundel (gewis nie in almal nie) is verkwikkend juis omdat dit nie verskonend is nie, maar 'n opregte en eerlike deurskouing is van gegewens. In die meeste gevalle is die vertellers duidelik bewus van die relatiwiteit van die verlede self en van die relatiwiteit van die verhaal wat nou daaroor vertel word. Die noodsaak van herdefiniëring van die self in die hede sowel as die onontkombaarheid daarvan om met die eie identeit te worstel, maak die visie op die verlede die makliker voorstadium van die denkproses.

Etienne van Heerden (1998:22) praat van die "ongemak met die geskiedenis" in postmodernistiese prosa, maar dit is asof die vertellers en skrywers van hierdie verhale heeltemal gemaklik is met die ongemak oor die geskiedenis. Dit is asof hulle die problematiese aard van die geskiedenis aanvaar en dit hier as instrument gebruik vir 'n saak wat nou dringender en meer gekompliseerd is. Hier word dus nie meer primêr of uitsluitend ondermynend met die geskiedenis omgegaan nie en die geskiedenis word ook nie meer opgekommandeer vir 
ideologiese mobilisasie nie. Die reeds ondermynde status van die geskiedenis word aanvaar en word hier instrument vir 'n verdere selfverkenning.

\section{Slot}

In 'n bundel van 34 verhale sal al die verhale vanselfsprekend nie van dieselfde gehalte wees nie (dit is ook inderdaad waar vir hierdie bundel), maar in die beste verhale in Boereoorlogstories het die geskiedenis lig en lugtig geword. Dit is nie moeisaam en moreel veeleisend soos sommige vroeë weergawes van die AngloBoereoorlog nie, dit dra nie meer die eenlynigheid van onverwerkte trauma nie, dit staan ook nie meer ten dienste aan die ideologie nie.

$\mathrm{Na}$ verloop van 'n eeu, is die geskiedenis van die Anglo-Boereoorlog al gemitologiseer en ook weer ontmitologiseer, dit was al altaarkleed en dit was al voetvel. Die nasate van diegene wat die oorlog meegemaak het, is gemaklik met die ongemak van die gebeure self en ook met die gebruik en misbruik van die historiese "feite". Wat nie beteken dat hierdie selfde gegewens nie weer en herhaaldelik gemitologiseer en ontmitologiseer sal word nie.

André P. Brink (1998:42) verduidelik die geproblematiseerde maar onontkombare bemoeienis met die geskiedenis so: "... the best we can do is to fabricate metaphors - that is, tell stories - in which, not history, but imaginings of history are invented. Myth may have preceded history, but in the long run it may well be the only guarantee for the survival of history".

Die onlangse verlede van Suid-Afrika is tans nog 'n pynlike werklikheid en aanwesigheid. Die belangrike rol van tyd word egter by die lees van historiese verhale duidelik. 'n Mens sien hoe gebeure wat te naby lê eintlik nog nie geskiedenis is nie. Die nabye verlede van Suid-Afrikaners sal nog veel verder moet teruggroei voordat dit met soortgelyke insig en gemak hanteer sal kan word.

\section{Bibliografie}

Brink, André. 1998. Stories of history: reimagining the past in post-apartheid narrative. In: Nuttall, Sarah \& Coetzee, Carli (eds.) Negotiating the past. The making of memory in South Africa. Cape Town : Oxford University Press. p. 29-42

De Kok, Ingrid. 1998. Cracked heirlooms: memory on exhibition. In: Nuttall, Sarah \& Coetzee, Carli (eds.) Negotiating the past. The making of memory in South Africa. Cape Town : Oxford University Press. p. 57-71.

Du Plooy, Heilna. 1998. Die omvang van die groter ontwerp. Tydskrif vir Christelike Wetenskap, Spesiale Uitgawe: 73-92, April.

Findley, C.V \& Rothney, J A.M 1990. Twentieth-Century World. Boston :Houghton Mifflin Fokkema, Redbad. 1997. Zomercursus "Aan de mond van al die rivieren". Universiteit van Utrecht, Nederland

Heidegger, Martin. 1949. Sein und Zeit. Tübingen : Neomarius Verlag. 
Musschoot, Anne Marie. 1998. Het autobiografische schrijven en het einde van het millennium. Lesing gehou by die Kongres van Suid-Afrikaanse Vereniging vir Neerlandistiek, Universiteit van Kaapstad, Julie 1998.

Van Heerden, Etienne. 1998 Die geding met die geheue: Kontemporêre fiksie se bydrae tot teoretiese besinnings oor die historiografie. New Contree, 42:21-34.

Van Heerden, Etienne. 1997. Postmodernisme en prosa. Kaapstad : Human \& Rousseau.

Wallbank, T.W., Taylor, A.M., Bailkey, N.M., Jewsbury, G.F., Lewis, C.J. \& Hackett, N.J. 1981. Civilization-past and present. Glenview, Illinois : Scott, Foresman \& Company 